\title{
Research on the Development Model of China's Live Stream Economy
}

\author{
Zihan Yang ${ }^{1, a}$ \\ ${ }^{1}$ Moses Brown School, Providence, RI 02906, The United States \\ ${ }^{a}$ Corresponding author's Email: norazihanyang@gmail.com

\begin{abstract}
Live stream economy has sprung up in China in recent years, especially after COVID-19. Different from other e-commerce models, live stream economy has the advantages of high efficiency, real-time, cost-effective. Therefore, in order to better understand this economy model, we analyse it from macroeconomics perspective to microeconomics perspective in this paper. From the macroeconomics perspective, we analyse the relevant factors that affect the economic scale of live stream by using some data analysis methods. From the microeconomics perspective, we analyse the data of a specific company from different aspects and find some interesting facts.
\end{abstract}

Keywords: Internet celebrity economy, Live Stream Economy, Electronic Commerce, Data analysis

\section{INTRODUCTION}

As the rapid development of mobile Internet and intelligent electronic devices, most teens and young adults tend to spend their time on mobile phones. In this context, some enterprises find that online sales of products can obtain higher profits than offline sales, because this can save the rental cost of the store [1]. For this reason, early E-commerce companies started to emerge in China, such as Taobao under Alibaba [2]. Taobao's model is that sellers upload pictures of their products, supplemented by specific parameters, prices and other information[3]. Customers can browse this information at will and determine whether to buy [4]. However, this model has a fatal disadvantage, that is, when customers buy clothes, they can't try them on like in physical stores, so they don't know whether this product is really suitable. Therefore, the refund rate is relatively high on Taobao. After reflecting on the above shortcomings, now the companies come with another e-commerce model-live stream commerce [5]. The model of this commerce is letting sellers started a live stream and introduce their products to customers directly.

If the customer has any requirements, for example, the anchor can let the model try on the dress after receiving corresponding requirements, so as to show the customer a vivid frame [6]. In China, this live stream commerce is most popular on TikTok [7], and it emerges from 1.4 billion Yuan in the year 2016 to 961 billion Yuan in the year 2020 [8].
Why live stream commerce expands so rapidly? and what factors are leading to the success of live stream commerce in China? How could China's live stream commerce model be applied to other countries? In this essay, we are going to explore those questions step by step.

Different from other studies that directly analyse the data, we analyse it by mining the deep information of data [9-11]. Also, starting from a macroeconomics perspective about overall live stream commerce in China to a microeconomics perspective about a specific cosmetic company in China, this paper provides a comprehensive view to help understand this new business model.

The rest of this paper is structured as follows: Section

2 discusses the factors that affect the development of live stream economy. And study on a specific company's data is detailed in Section 3. Section 4 analyzes the enlightenment of China's live stream economy model to the U.S. market. Finally, the work is concluded in Section 5.

\section{RESEARCH ON THE FACTORS OF LIVE STREAM ECONOMY}

\subsection{Background}

Live stream started in 2005 and broke out in the year 2016. In the early years, from 2005-2016, most live 
streams appeared on PC platform. But things turned to change around 2017, live streams transferred from PC platform to mobile platform. As mentioned before, most of the live streams that take place on PC are entertainment, such as e-sports, dancing or singing shows. However, when the phenomenon of live stream appears on the mobile platform, it reflects more of its commercial value. Anchor can communicate with the company directly to get the best-selling price in his/her own stream. Audiences tend to buy products while watching the live stream because they could save about $10 \%$ of their money compared to other commercials. Taking Taobao (online store under Alibaba) as an example, active live stream audience increased from 658 thousand in March 2019 to 3.756 million in March 2020, over $470 \%$ growth rate in just one year. In China, the volume of live stream commercials reached 451 billion $\mathrm{RMB}$ in 2019. In order to explain why and how live stream commercials could increase dramatically, we select 20 factors from different perspectives which are shown in Table 1, and collect the data of these 20 factors from 2016 to 2020 [12].

Table 1. Definition of 20 factors

\begin{tabular}{|c|c|}
\hline Factor & Definition \\
\hline$x_{1}$ & User scale of China's online live stream industry \\
\hline$x_{2}$ & China's e-commerce transaction volume \\
\hline$x_{3}$ & China mobile e-commerce market scale \\
\hline$x_{4}$ & Online retail sales in China \\
\hline$x_{5}$ & $\begin{array}{c}\text { Proportion of online retail sales in total retail sales } \\
\text { of social consumer goods }\end{array}$ \\
\hline$x_{6}$ & Number of e-commerce employees in China \\
\hline$x_{7}$ & $\begin{array}{l}\text { Business volume of express service enterprises in } \\
\text { China }\end{array}$ \\
\hline$x_{8}$ & Online shopping user scale \\
\hline$x_{9}$ & The number of MCN companies \\
\hline$x_{10}$ & The scale of MCN market \\
\hline$x_{11}$ & Scale of Internet users in China \\
\hline$x_{12}$ & Scale of rural Internet users in China \\
\hline$x_{13}$ & Internet penetration in rural China \\
\hline$x_{14}$ & Scale of urban Internet users in China \\
\hline$x_{15}$ & Internet penetration in urban areas of China \\
\hline$x_{16}$ & Per capita disposable income in China \\
\hline$x_{17}$ & Per capita disposable income in rural China \\
\hline
\end{tabular}

$\begin{array}{cc}x_{18} & \begin{array}{c}\text { Per capita disposable income in Chinese cities and } \\ \text { towns }\end{array} \\ x_{19} & \text { Total global retail sales } \\ x_{20} & \text { Global online retail sales }\end{array}$

\subsection{Data Analysis}

\section{Data preprocessing}

As mentioned above, we collect the corresponding data of the 20 factors, and we try to find how these factors affect the scale of China's live e-commerce $\boldsymbol{\theta}$. However, these data cannot be used directly since the incompleteness of data and existence of abnormal values. Therefore, we first take the process of abnormal value elimination and replenish the missing data by regression method with the collected data.

Then, we have to normalize the data to complete the data preprocessing. The data we collect have different dimensions and orders of magnitude, the results will produce errors or deviations if we analyze them directly. Usually, data can be normalized by the following methods:

-Min-max normalization

-zero-mean normalization (z-score normalization)

- Log function conversion

-Arctan function transformation

Here we use the second $\mathrm{z}$-score normalization method to process our data. The conversion formula is as follows:

$$
x^{*}=\frac{x-\bar{x}}{\sigma}
$$

where $x$ is the original data, is the mean value of sample data, $\sigma$ is the standard deviation of sample data, and $x^{*}$ is the normalized value.

\section{Factors Cluster}

Qualitative investigation of 20 factors that reflect the development of the live stream economy shows that there is a strong correlation between some factors. For example, there may be a strong correlation between the size of China's mobile e-commerce market and China's online retail sales. In order to verify this point, we calculate the correlation between each factor in MATLAB. Here we use the Pearson product-moment correlation coefficient formula to do the calculation, which is given as:

$$
\begin{gathered}
\rho_{\theta, x_{n}}=\frac{\operatorname{cov}\left(\theta, x_{n}\right)}{\sigma_{\theta} \sigma_{x_{n}}}=\frac{E\left[\left(\theta-\mu_{\theta}\right)\left(x_{n}-\mu_{x_{n}}\right)\right]}{\sigma_{\theta} \sigma_{x_{n}}} \\
\text { where } \operatorname{cov}\left(\theta, x_{n}\right) \quad \text { represents the sample }
\end{gathered}
$$
covariance of $\boldsymbol{\theta}$ and one factor. 
The correlation coefficient is shown in Table 2.

Table 2. Correlation coefficient of 20 factors

\begin{tabular}{|c|c|c|c|c|c|}
\hline factors & $x_{1}$ & $x_{2}$ & $x_{3}$ & $x_{4}$ & $x_{5}$ \\
\hline $\begin{array}{c}\text { correlation } \\
\text { coefficient }\end{array}$ & 0.905 & 0.835 & 0.920 & 0.869 & 0.914 \\
\hline factors & $x_{6}$ & $x_{7}$ & $x_{8}$ & $x_{9}$ & $x_{10}$ \\
\hline $\begin{array}{c}\text { correlation } \\
\text { coefficient }\end{array}$ & 0.908 & 0.968 & 0.902 & 0.998 & 0.976 \\
\hline factors & $x_{11}$ & $x_{12}$ & $x_{13}$ & $x_{14}$ & $x_{15}$ \\
\hline $\begin{array}{c}\text { correlation } \\
\text { coefficient }\end{array}$ & 0.961 & 0.998 & 0.994 & 0.905 & 0.923 \\
\hline $\begin{array}{c}\text { factors } \\
\text { correlation } \\
\text { coefficient }\end{array}$ & 0.892 & 0.921 & 0.877 & 0.896 & 0.928 \\
\hline
\end{tabular}

It can be seen from Table 2 that there is a strong correlation between $\boldsymbol{\theta}$ and the 20 factors. And at the same time, there is a certain correlation between the various factors which is not shown in the table. Therefore, we consider selecting some representative variables from these 20 factors. According to the characteristics of the collected data, here we introduce the R-type clustering method to divide 20 factors into several typical classes, and then use the most relevant factor to represent the corresponding class. According to the correlation coefficients between factors, R-type clustering method can group the factors with strong correlation into one class, and the similarity among classes are measured by the class average method. Similarly, this process also can be processed by Matlab and the clustering tree graph is shown in Figure 1.

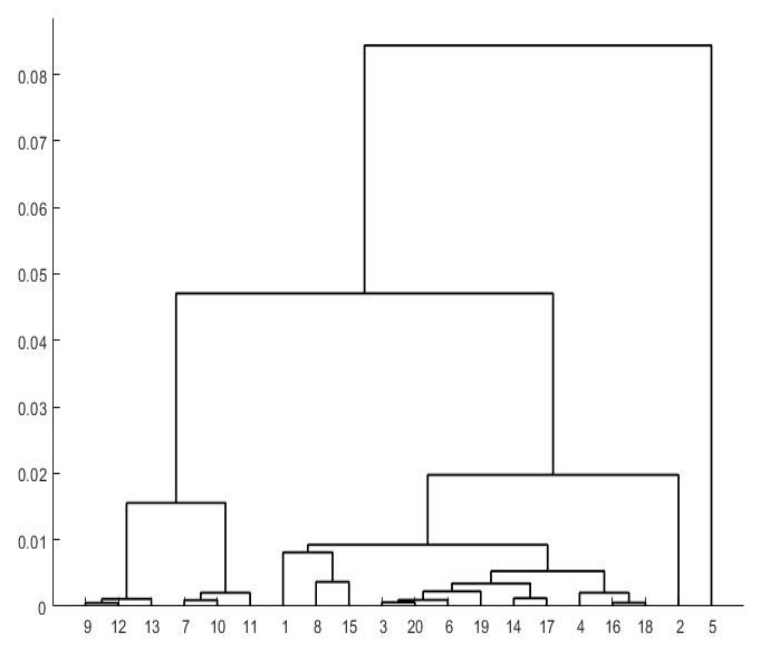

Figure 1. Clustering tree graph

From the cluster result shown in Figure 1, we can find that it is reasonable to divide these 20 factors into three, four or six classes. Since we choose 20 factors, it would be more appropriate to divide it into six classes, and the results of classification are shown in the Table 3 below.
Table 3. Classification results of 20 factors

\begin{tabular}{cccccc}
\hline Category & Factors \\
\hline 1 & $x_{3} x_{4} x_{6} x_{14} x_{16} x_{17} x_{18} x_{19} x_{20}$ \\
\hline 2 & $x_{1} x_{8} x_{15}$ \\
3 & $x_{9} x_{12} x_{13}$ \\
4 & $x_{7} x_{10} x_{11}$ \\
5 & $x_{2}$ \\
6 & $x_{5}$ \\
\hline
\end{tabular}

Finally, we highlight the most relevant factor of each class in Table 3.

\subsection{Conclusion}

After clustering and correlation analysis, we identify six factors as shown in Table 3 that have a great impact on the scale of China's live e-commerce. According to the corresponding relationship shown in Table 1, we know that the six factors are:

- China's e-commerce transaction volume

-Proportion of online retail sales in total retail sales of social consumer goods

-The scale of MCN market

-Scale of rural Internet users in China

-Internet penetration in urban areas of China

- Global online retail sales

To sum up, we can draw the following conclusions:

$>$ Development of China's live e-commerce is inseparable from the background of the good development momentum of China's e-commerce, which is embodied in the increasing transaction volume and the increasing proportion in the national economy

$>$ China's action to build a network power not only has a large number of Internet users in rural areas, but also has a high level of network popularity in urban areas. All these promote the convenience of information transmission and the popularization of new things, which are the basis of the emergence and prosperity of the live e-commerce.

$>$ Last but not least, China's economy is not decoupled from the world economy. As China has put forward, interplay between internal and external economic flows should be stressed in the course of constructing the new development dynamic. 
Therefore, the development of world e-commerce economy also affects China's live e-commerce.

\section{RESEARCH ON A SPECIFIC COMPANY'S DATA}

After the analysis of economic data at the macro level above, we can dig out several factors that have a significant impact on the live stream economy. In this section, we study the live stream economy from a micro perspective, that is, from the perspective of a specific company's data. The data we use in this paper comes from Usir, which is a company focusing on e-commerce live marketing.

The research is carried out from the following aspects:

- Consumer Profile

-Product analysis

- Marketing promotion

-Live stream data analysis

\subsection{User Profile}

User profile, is an effective tool to outline target users and associate user demands with design direction, and user profile has been widely used in various fields. In the process of practical operation, we often connect the user's attributes and behavior with the expected data transformation with the most simple and close to life words. As the virtual representative of actual users, the user role formed by user profile is not constructed outside the product and market, but needs to be representative to represent the main consumers and target group of the product [13].

User profile was initially applied in the field of e-commerce. In the context of the big data era, user information is flooded in the network, abstracting each specific information of users into labels, and using these labels to concretize the user image, so as to provide targeted services for users.

When it comes to live stream economy, user profile is used to analyze the attributes of consumers, i.e., gender, age, region and so on. With these attributes, the anchor can push and sell products more accurately and formulate more reasonable sales strategies.

\section{A.User age analysis}

In this part, we analyze the consumer age of Usir, try to explore what the user base is like. We summarize the user age distribution of Usir into Figure 2, and we can find that the so-called post-95 has become the main force of live stream consumption, with over 71 percentage.

It can be seen that most users watching live streams are young. Therefore, the standardization, verticality and refinement of live stream content by major live stream platforms need to be carefully planned to correctly guide young users and attract users to spontaneously understand the product value, so as to promote the conversion rate of private domain live traffic.

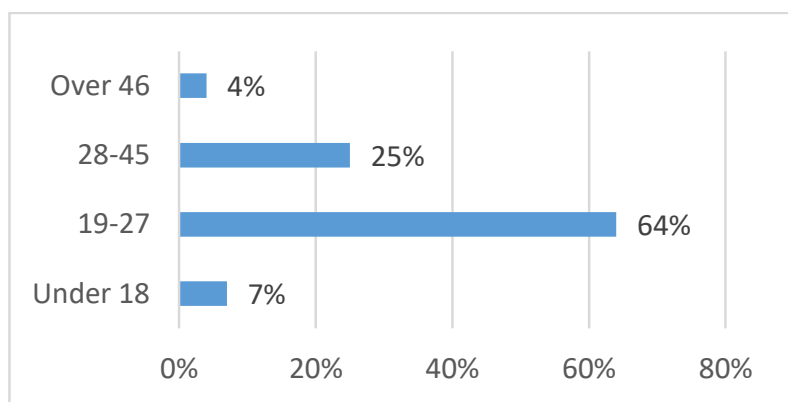

Figure 2. Proportion of Consumers of Different Age Groups

\section{B.User gender distribution}

As we already know that the main consumers are young people, we also need to determine their main gender groups. We show the gender distribution of Usir's users in the form of pie chart as shown in Figure 3. From this figure we can see that women are the main consumers, which is closely related to women's consumption habits, the types of goods promoted by businesses and many other factors.

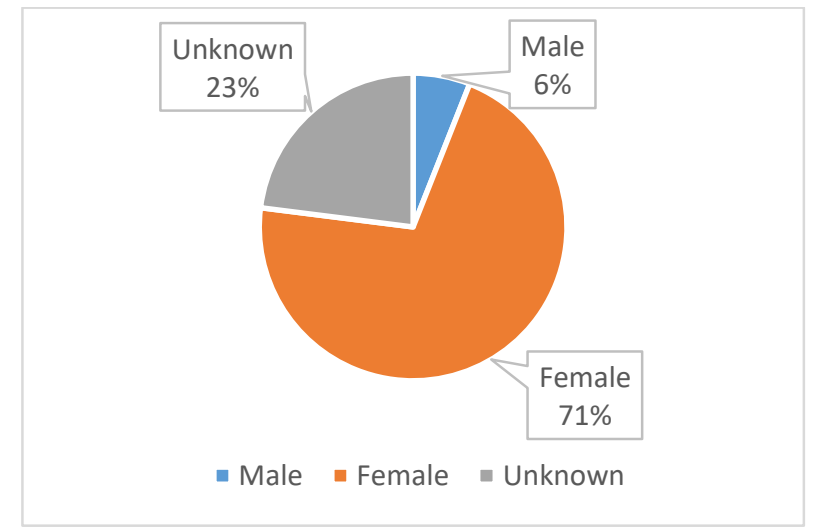

Figure 3. Gender Distribution Ratio of Consumers

\section{C.Regional Distribution of Consumers}

In this part, we hope to find some new point from the perspective of user regional distribution.

In Figure 4, we can find that $60 \%$ of the Usir's consumers come from first-tier and new first-tier cities, which means that people in big cities are more willing to watch their live stream and buy the products they promote.

In Figure 5, we summarize the proportion of users from major cities of China. We can find that consumers from Shanghai are the most, followed by Hangzhou. It may mean that these two cities have more target users of Usir. 


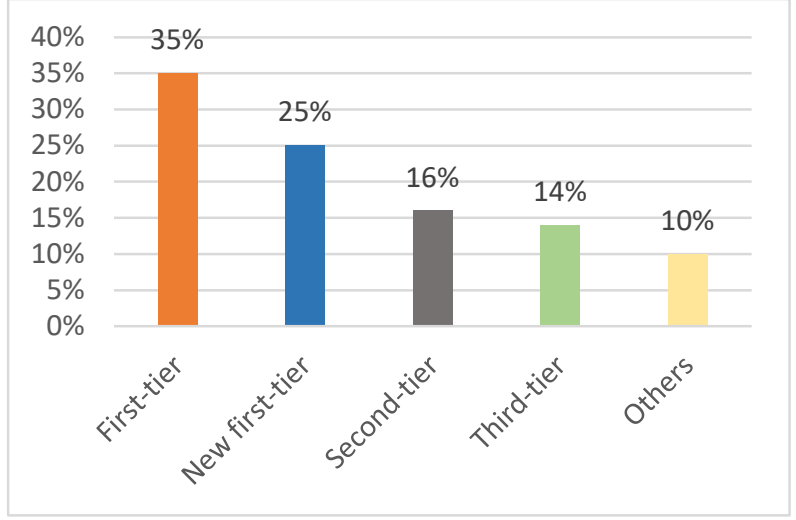

Figure 4 User's City Level Statistics

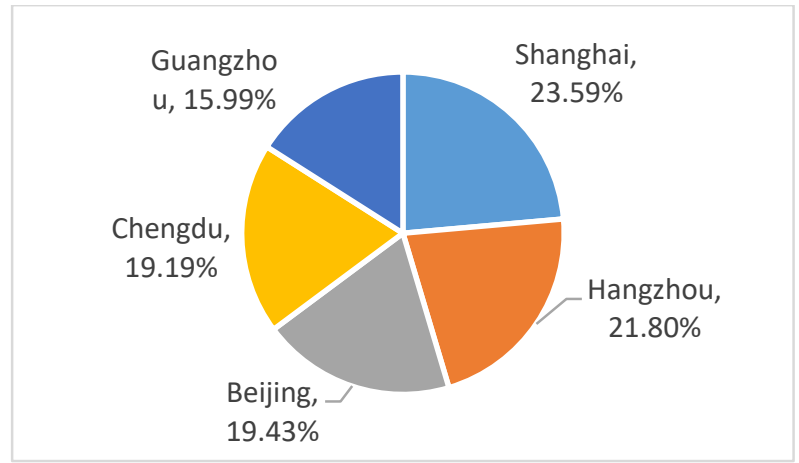

Figure 5. User Distribution of Five Major Cities

\subsection{Product analysis}

In this section, we analyze the products promoted by Usir. Categories, prices, advantages of products will be analyzed in the following content.

By analyzing these characteristics of products, we could get a comprehensive view of how consumers choose each product of Usir and which product is mainly popularizing.

Because we have analyzed the company's target consumers' characteristics above, we can then analyze the design concepts and pricing solutions of Usir.

\section{A.Category}

Since Usir is a cosmetic company, and the products vary in make-up field. In most cases, beauty product development needs to go through the enterprise's internal and external creative collection, the formation of a variety of creative prototypes, in the form of development proposals. Before a new product is formally developed, a comprehensive feasibility analysis of various creative prototypes, such as formula credibility, production feasibility, cost feasibility, regulatory feasibility and conceptual feasibility analysis, is required before the final project can be developed.

From the basic foundation, lipstick to eyeshadows, Usir covers almost every kind of cosmetic products.
However, since Usir is at the starting point, it focuses more on small daily products such as lipsticks and eye linear rather than foundation. In Figure 6, we can easily find that lipstick and eye linear account for $60 \%$ of all the products of Usir, and concealer only hold $10 \%$.

This shows that at the very beginning, massive investment in the development and sale of small cosmetic products such as lipsticks and eyeliner can reduce costs and open the market quickly, because the two products consume most and demand a lot.

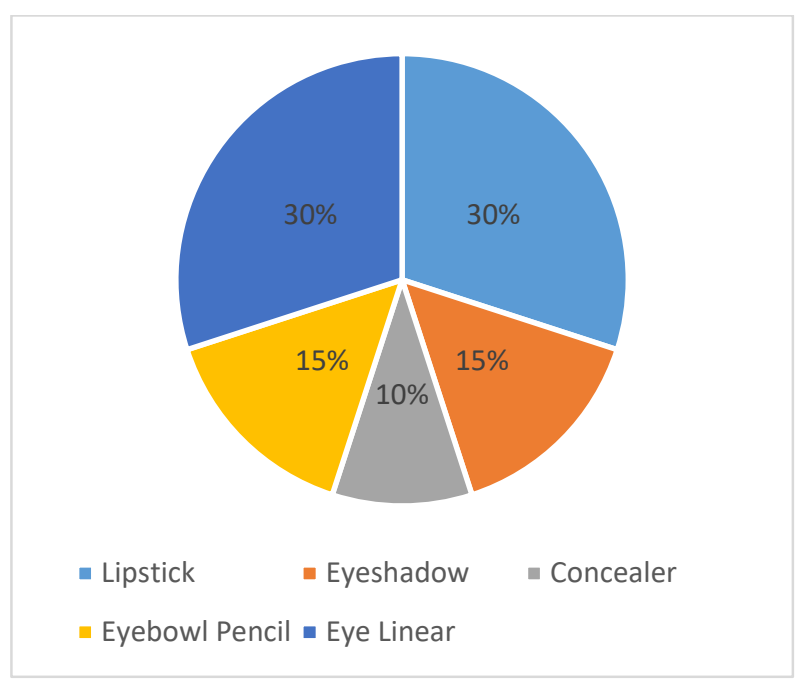

Figure 6. Product category

\section{B.Prices}

In the product pricing strategy, "civilianization" is the main goal. Usir's pricing strategy is "extremely cost-effective" and the average price of a product is less than a third of that of a well-known international brand. In recent years, generation $\mathrm{Z}$ young people have gradually become the main force of new Internet consumption, they do not follow the big brands, but are more interested in new brands, new products and new experiences, and they are also very price sensitive, the ultimate cost-effective products are more in line with their needs. Most products are under $¥ 100$, even the most expensive eye shadow is only $¥ 179$. The average tag prices vary from $¥ 79$ to $¥ 179$. Since the current rise of live stream with goods mode, all businesses are competing to enter, resulting in fierce price competition. The sales price of each live stream is different, which mainly depends on the popularity brought by the anchor and guests, which can generally be reduced by about $¥ 10$ as shown in Figure 7 . 


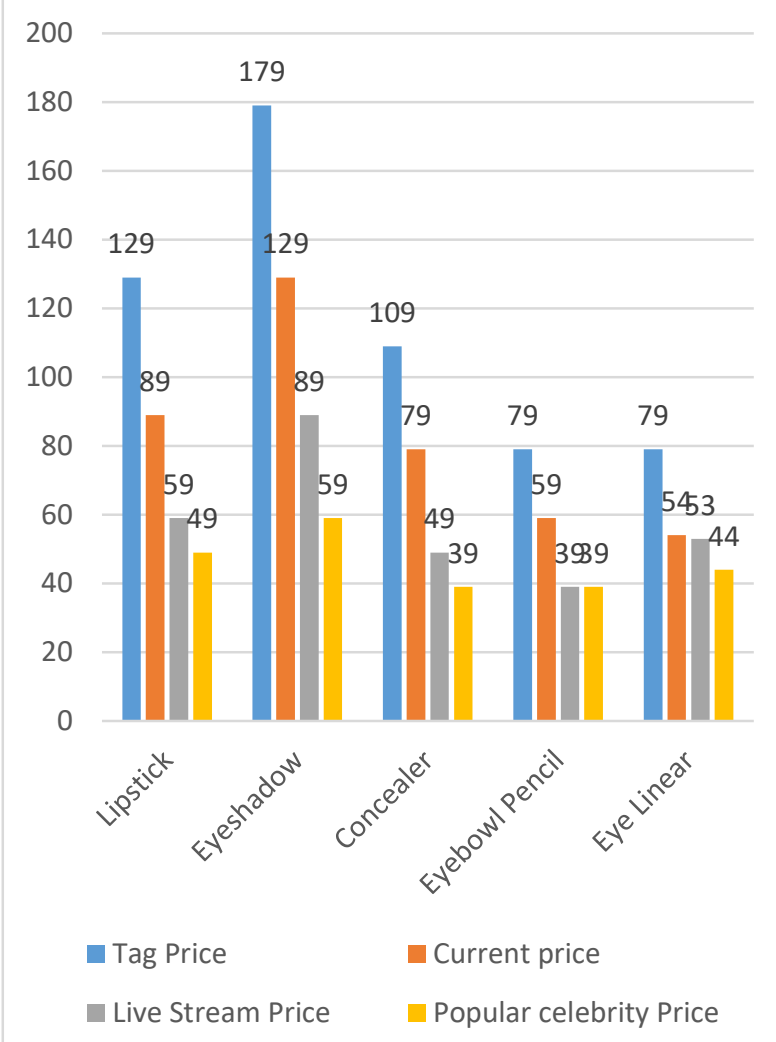

Figure 7. Prices of different products in different channels

\subsection{Advertising}

For a new cosmetics company, one of the most important steps is to promote it. No matter how good the product quality is, how low the price is, if there is no consumption channel, Usir cannot open the market. Therefore, advertising is a very necessary step. Traditional promotions, such as billboards or magazines, are not as practical and timely as they used to be. And traditional propaganda methods require high investment in the short term, but they do not necessarily have high returns [14]. So Usir uses a new, modern way to promote.

\section{A.Promotion/Channel}

Because the target consumers are age in the 18-24 range, Usir chose the fastest online promotion. Taobao, as China's Amazon, has become Usir's first promotion channel, but not the main channel. Modern young people spend a lot of time on short video and picture platforms such as Tik Tok and Red (like pinterest in China), these two channels can quickly and easily deliver announcements directly to target customers. And because consumers on these channels usually spend less than a minute browsing, Usir is looking for a large number of vloggers and bloggers to do multiple recurring promotions. The main channels that Usir use are shown in Figure 8.

Promotional bloggers range from passers-by to well-known KOLs to stars, covering almost every kind of crowd as shown in Table 4. The number of bloggers of each type is as shown in the Figure 9 which can help Usir to make the right marketing choices.

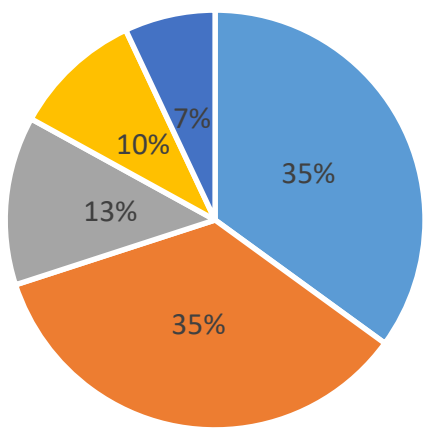

- Tik Tok = Red BiliBili - Tao Bao - Weibo

Figure 8. Main channels of Usir

Table 4 Definition of different levels of internet celebrity

\begin{tabular}{cc}
\hline level & Number of fans \\
\hline Passersby & $<300$ \\
Amateur & $300-5000$ \\
Junior Master & $5 k-50 k$ \\
Waist Master & $50 k-500 k$ \\
Head Master & $500 k-1$ million \\
Well-Known KOL & $>1$ million \\
Stars & Movie Stars \\
\hline
\end{tabular}

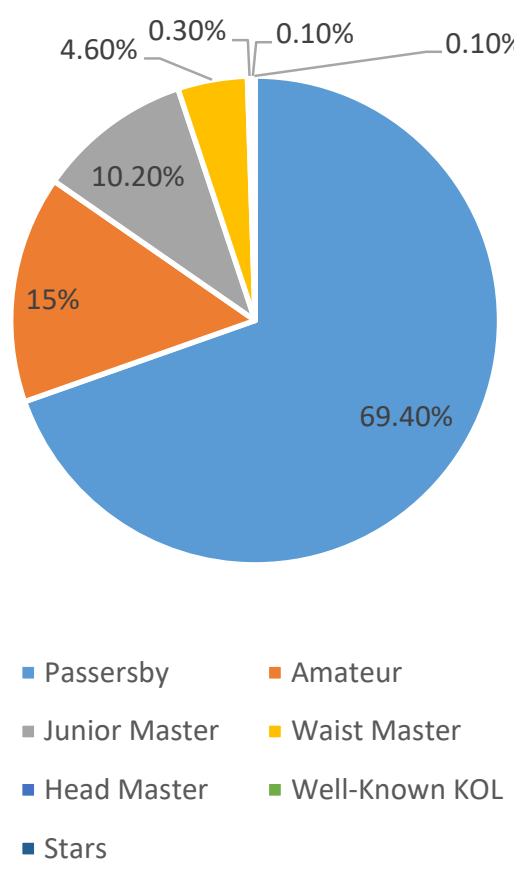

Figure 9. Number of bloggers of each type 


\section{B.Promotional effect}

First, Usir works with KOLs, but in fact the number is very small. The main purpose is to build momentum. Then, the head of the talent will track the relevant stars, and discuss the possibility of cooperation with them, and the conditions given will be more relaxed than some general internet celebrity.

With the endorsement of top stars, waist anchors and junior anchors will follow the wind, so it will be very easy to cooperate with them.

Finally, driven by the popularity of various stars, we created a prosperous scene of using Usir products on social platforms, so as to guide ordinary users to follow suit and start sharing their product use notes on platforms such as Red. The promotional effect of Usir can be seen from Figure 10 clearly, it shows the driving force under the star effect.

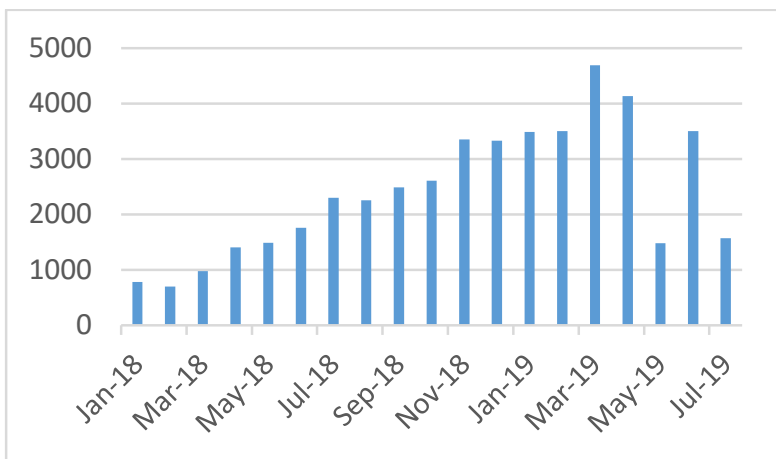

Figure 10. Number of Relating Posts on Red

Sales surged during the period when it was heavily promoted (Shown in Figure 11, 618 is a famous shopping festival in China). This is the real-time advantage of network promotion.

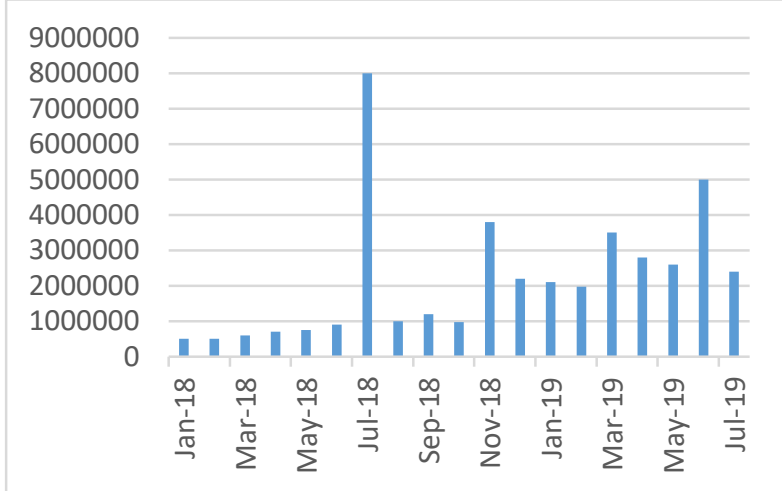

Figure 11. Quantity of Sale

\section{C.Live stream}

The most important and convenient way to sell is through live streaming. In the process of live stream, the host can better communicate with consumers and display goods from all aspects more conveniently [15].

At the same time, compared with the prices mentioned above, customers can always buy their favorite products at a lower preferential price through the live stream.

To give a more intuitive example, on the 618 night of promotion, Chao Ran, a vlogger with 2.59 million followers on Tik Tok did a live streaming selling Usir's eye linear. As a result of this live stream, 288k consumers watched the live stream, and the final transaction order volume was $20 \mathrm{k}$. Meanwhile, the overall profit was increased by $60 \%$ after this live stream, and the overall number of consumers visit was increase by $30 \%$.

All this shows the advantages of the live stream sales model, which is the reason that Usir chooses to focus on live stream. Currently, live sales account for $55 \%$ of Usir's total sales as shown in Figure 12.

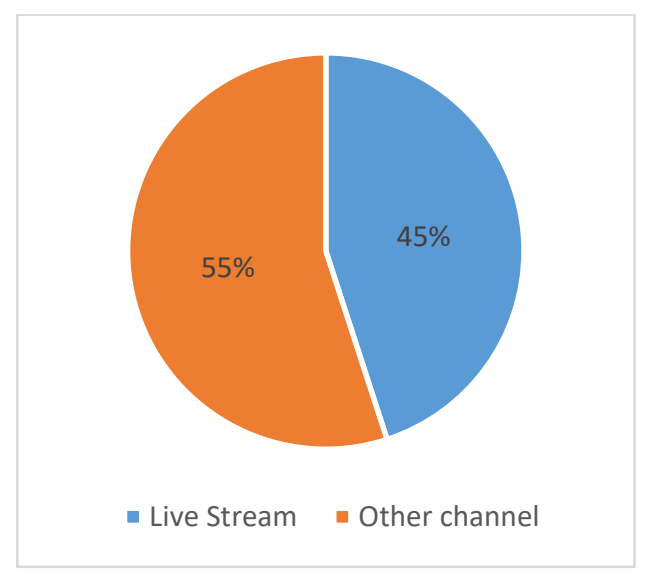

Figure 12. Proportion of live stream sales

\section{CONCLUSION}

In this paper, we analyzed the development and model of China's live stream economy from macroeconomics perspective to microeconomics perspective. First we analyzed the potential factors that may affect the live stream economy, and then use some data analysis methods such as preprocessing, cluster and correlation analysis to explore the relationships from the collected data. Second, from the microeconomics perspective, we analyzed the data of a specific company called Usir and hope to find some confirmation of the macroeconomics analysis in section 2 . We analyzed the operation mode from three aspects, which are user profile, product analysis and advertising, and find that online promotion is the key to the China's live stream economy, which can finally leads to huge profits to Usir. Therefore, the model of live stream economy is worth learning and promoting in other countries.

\section{ACKNOWLEDGMENT}

Thank Mr. Wu and Ms. Chen for their careful guidance and help. 


\section{REFERENCES}

[1]Zhao Q, Chen C D, Cheng H W, Wang J L (2018). Determinants of live streamers' continuance broadcasting intentions on Twitch: A self-determination theory perspective. Telematics and Informatics, 35, 2: 406-420.

[2]Tang W C, Zhu J(2020). Informality and rural industry: Rethinking the impacts of E-Commerce on rural development in China. Journal of Rural Studies, 75: 20-29.

[3]Wang Yesong(2020). “Agriculture, Rural Areas and Farmers" marketing strategy in the context of Internet celebrity economy. Market Research, no.5, pp: $38-40$.

[4]Xu Lan (2018). Research on the strategy of corporate marketing under the background of Internet celebrity economy. Chinese Market, no.35, pp: 133-134.

[5]Geng, R., Wang, S., \& Chen, X. (2019). Internet Celebrity Endorsement: How Internet Celebrities Bring Referral Traffic to E-commerce Sites? In PACIS 2019 Proceedings. 193.

[6]Lejie, Y. (2021). Analysis of Internet Marketing from the Perspective of "Internet Celebrity Economy". Journal of Frontiers in Educational Research, 1(3), 115-119.

[7]Wang Kaili(2020). Research on TikTok Internet celebrity economic marketing. Market Weekly, no.2, pp: 95-96.

[8]Rao, Y., Zhang, K., \& Li, L. (2010). The econometric analysis of the relationship between chinese e-commerce transactions and gdp. In 2010 International Conference on Management of e-Commerce and e-Government (pp. 248-251). IEEE.

[9]Wei, Z., \& Zhou, L. (2011). Case study on B2C e-commerce of Chinese apparel industry. In 2011 International Conference on Computer Science and Service System (CSSS) (pp. 2141-2144). IEEE.

[10]Ding, Z., Tang, C., \& Wei, H. (2020). Research on the Development Strategy of" E-Commerce+ Live Broadcast" Mode under the Internet Celebrity Economy. In 2020 International Conference on E-Commerce and Internet Technology (ECIT) (pp. 20-23). IEEE.

[11]Zheng, Y., \& Ni, W. (2020). Analysis on Transformation and Development of Traditional Enterprise Based on Internet Celebrity Economy. Journal of Education and Praxis Research. 1(6), $1-9$.
[12]Li, M., Shao, J., Pang, H., \& Zou, Y. (2017). Study on Main Consumption Items and Corresponding Influencing Factors of College Students in the Internet Celebrity Economy.

[13]Wei, H., \& Wang, L. (2016). Study on Media Marketing under the "Internet + " Background: Internet Celebrity Economy.

[14]Li Pingping, $\mathrm{Hu}$ Min, Qin Min, Luo Menghan(2019). Analysis of Internet celebrity marketing model and economic development trend of Internet celebrity in the self-media era. China Business Forum, no.10, p: 13-15.

[15]Kang Xinen, Zhong Sili (2020). Analysis of marketing innovation in the era of Internet celebrity economy. Quality and Market, no.12, pp: 94-96. 